\title{
DIREITO EMPRESARIAL CONTEMPORÂNEO: O CASO BANKSY
}

MARISA ForghiERI

Psicóloga clínica e gestora, com Pós-Doutorado em Psicologia Social e do Trabalho da USP, Doutora em Psicologia Clínica pela PUC-SP, Mestre em Psicologia do Desenvolvimento pela USP, graduada em Psicologia pela PUC-SP, Professora Titular da Universidade Paulista e Docente Permanente do Programa de Mestrado em Direito Empresarial da Faculdade de Direito Milton Campos.

Carlos A. Rohrmann

Doutor em Direito pela Universidade da Califórnia em Berkeley. Professor de Direito Virtual e de Direito Empresarial da Faculdade de Direito Milton Campos. Professor titular e Diretor da Faculdade de Administração Milton Campos. Coordenador-Geral da Pós-Graduação das Faculdades Milton Campos e Coordenador Didático do Mestrado em Direito Empresarial da Faculdade de Direito Milton Campos. Mestre em Direito pela Universidade da Califórnia em Los Angeles - UCLA. Mestre em Direito Comercial para UFMG. Bacharel em Direito (FDMC) e em Ciência da Computação (UFMG). Membro da Academia Mineira de Letras Jurídicas, titular da Cadeira Acadêmica número dezesseis, patrono Raul Soares de Moura. Procurador do Estado de Minas Gerais. Advogado.

\section{Resumo}

O Direito empresarial e as grandes galerias de arte são provocados pela obra do artista inglês Banksy; este ensaio discute as novas perspectivas para os artistas urbanos e para o Direito empresarial na contemporaneidade. Este texto apresenta, sob uma perspectiva interdisciplinar, algumas áreas de aplicação do direito de empresa, especialmente quanto à proteçáo, ou náo, da propriedade intelectual, no caso da arte urbana. $\mathrm{O}$ artigo apresenta o caso Banksy e suas obras em ambientes urbanos, ora públicos, ora privados, e, a partir de uma revisão histórica sobre a proteção da propriedade intelectual, ainda que se trate da proteção de uma obra de arte, analisa os desafios que a inusitada criação do autor Banksy coloca para o direito de empresa.

\section{Palavras-chave}

Direito Empresarial; Banksy; Arte urbana; Propriedade intelectual.

\section{Abstract}

The interaction between business law and art galleries is hit by the work of the English artist Banksy. This article addresses new prospects for urban artists and business law 
in contemporary times. This paper presents, under an interdisciplinary perspective, some areas of application of business law, especially the protection, or not, of intellectual property, in the case of urban works of art. The article presents the case Banksy and his work in the urban environment, sometimes in public property, sometimes in private buildings, and, from a historical review of the protection of intellectual property, especially in the case of protection of a work of arts, this text examines the challenges that the unusual creation of Banksy presents to contemporary business law.

\section{Key words}

Business Law; Banksy; Urban art; Intellectual property.

\section{Introdução}

A arte contemporânea vem sendo discutida e analisada sob diversas perspectivas. Saturada e deslocada, transcendendo o espaço expositivo clássico, a arte exige do expectador um novo modelo para a sua compreensão. (CAUQUELIN, 2005).

Variadas e renovadas propostas artísticas são expostas em importantes museus e galerias, pelo mundo. Tais galerias, de modo objetivo e, ao mesmo tempo, subjetivo, elegem os artistas e as tendências que representam e caracterizam um tipo de vanguarda. Ninguém imaginou ou previu, entretanto, que uma potente manifestação de vanguarda seria uma provocação ou, por assim dizer, uma livre contribuição para o acervo da Tate Gallery.

Em 2003, o artista inglês Banksy entrou na Tate Gallery e ali colou o seu quadro, comprado em uma feira de antiguidades de Londres - uma pintura a óleo sem assinatura sobre a qual ele aplicou uma faixa de isolamento de ocorrência policial. Essa instalação durou duas horas, devido à cola de má qualidade (BANKSY, 2005), e foi fotografada pelo artista. Anos mais tarde, mesma a Tate Gallery comprou, por uma quantia não divulgada, uma obra de Bansky, incluindo-a em seu acervo permanente.

Banksy é um artista urbano que, além de trabalhar com arte de estêncil e grafite nas ruas, decidiu colocar sua obra em um espaço anteriormente reservado apenas para um restrito grupo de artistas.

A Arte que admiramos é feita por apenas uns poucos escolhidos. Um pequeno grupo cria, promove, comercializa, exibe e decide seu sucesso. Apenas poucas centenas de pessoas em todo o mundo têm realmente a palavra. Quando se vai a uma galeria de Arte, você é apenas um turista olhando a sala de troféus de alguns milionários. BANKSY, 2005. 
A intervenção de Banksy na Tate criou uma nova perspectiva para se reagir, pensar e compreender a arte contemporânea, bem como os direitos próprios dos artistas e das galerias de arte.

O talento único de Banksy o coloca à frente de um movimento totalmente novo no mundo das artes: a arte de rua - ou arte urbana. Em 2010 a revista Time o incluiu no ranking das cem pessoas mais influentes do mundo, junto a personalidades como Barak Obama e Steve Jobs. Banksy mandou uma foto de si mesmo com um saco reciclável cobrindo seu rosto; ele é o único artista do século XXI que é famoso e desconhecido, ao mesmo tempo.

Para além da proposição de um novo paradigma para se pensar a arte contemporânea e seus espaços expositivos, Banksy também questiona a uniformização dos espaços públicos, em nome de um padrão entediante de higiene.

Quais as fronteiras entre o espaço público, suporte da arte urbana, e os espaços expositivos tradicionais? Como uma obra de arte urbana, que tem como suporte um muro, pode ser vendida em uma galeria? Como se dá a autenticação dessas obras? Como o espaço público pode ser renovado por meio da arte? Qual proteção, se é que o autor deseja alguma, o direito confere às obras?

A seguir, trazemos imagens com alguns exemplos das obras de Banksy, no espaço urbano.

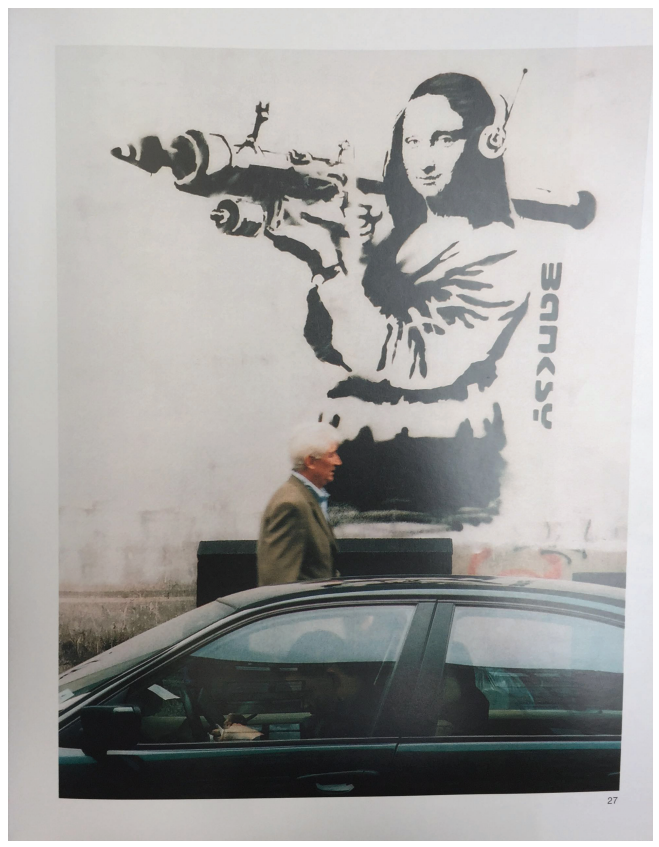

BANKSY. Guerra e Spray. Mona Lisa, p. 27 


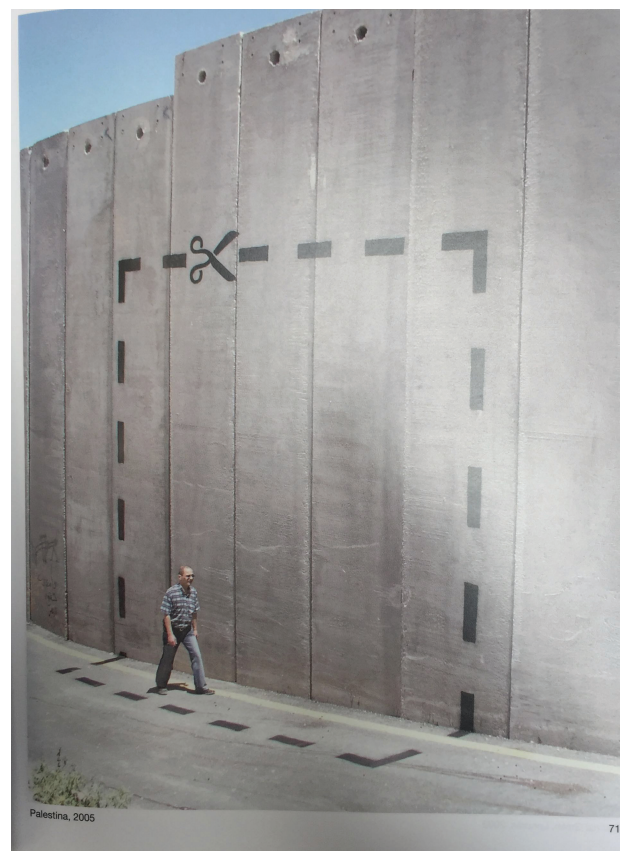

BANKSY. Guerra e Spray. Palestina, p. 71

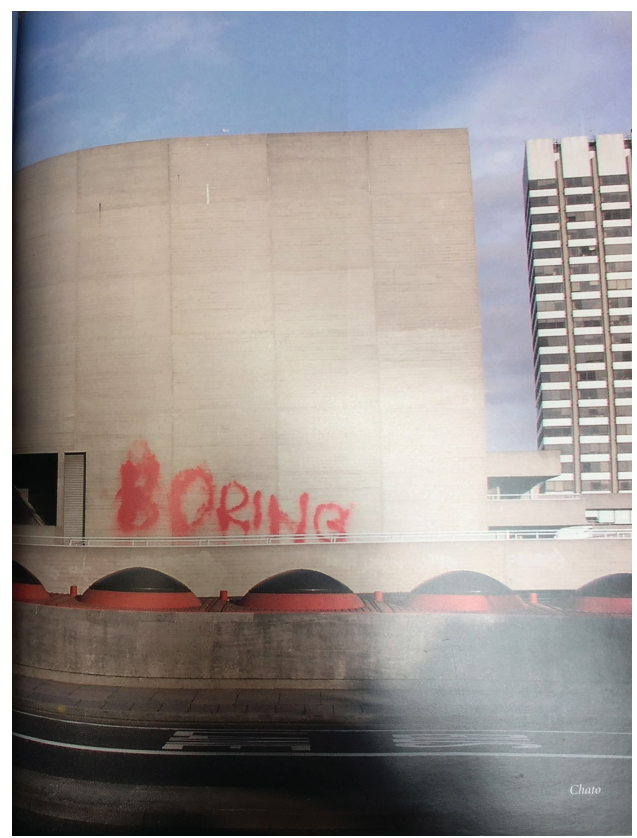

BANKSY. Guerra e Spray. Boring p. 127 


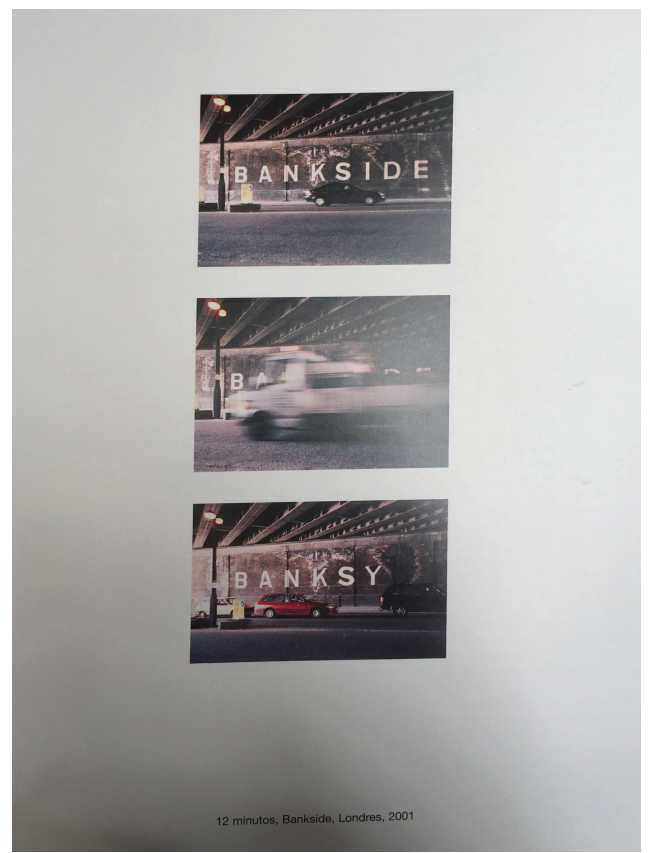

BANKSY. Guerra e Spray. Bankside, p. 7

\section{Direito Empresarial Contemporâneo, Propriedade Intelectual e Arte Urbana}

Uma vez que um dos mais interessantes aspectos que o direito contemporâneo se interrelaciona com o movimento da arte urbana é a valorizaçáo do local onde a arte é inserida por meio do acréscimo à propriedade, invocaremos a proteção ao direito de propriedade intelectual.

Analisaremos o direito que protege a propriedade intelectual após uma resumida pesquisa acerca do direito de propriedade, propriamente dito. Vamos buscar uma base nas origens do instituto no próprio direito romano.

O direito de propriedade é constitucionalmente protegido pela Constituição da República de 1988 e também pelo Código Civil brasileiro.

1 CR-88, art $5^{\circ}$, caput e incisos XXII e XXIII, verbis:

"Art. 50 Todos são iguais perante a lei, sem distinção de qualquer natureza, garantindo-se aos brasileiros e aos estrangeiros residentes no País a inviolabilidade do direito à vida, à liberdade, à igualdade, à segurança e à propriedade, nos termos seguintes:

(...)

XXII - é garantido o direito de propriedade;

XXIII - a propriedade atenderá a sua função social”. 
O Código Civil de 2002, na esteira do Código Civil de 1916, não define o direito de propriedade, apenas enumera os direitos do proprietário (usar, gozar, dispor e o direito de rever, reivindicar a coisa de quem quer que a possua ou detenha injustamente). ${ }^{2}$

Pode-se buscar a origem dos direitos do proprietário no direito romano, ou, mais especificamente, no Corpus Iuris Civilis. ${ }^{3}$

O Corpus Iuris Civilis, que foi escrito em Constantinopla, muito depois da queda do Império Romano do Ocidente, quando Justiniano era o imperador do Império Romano do Oriente - Império Bizantino. ${ }^{4}$ A sua edição foi uma tentativa, por parte do Imperador, de resgatar o esplendor do direito romano.

$\mathrm{O}$ direito de propriedade, no direito romano, era visto como o "direito que liga o homem a uma coisa". Por se tratar de um direito potencialmente absoluto, o direito de propriedade possibilitaria, ao seu titular, retirar da coisa todo o uso e toda a utilidade possíveis. ${ }^{5}$ Houve, mesmo no direito romano, ao longo dos anos, uma evolução no sentido de se tornar o direito de propriedade menos individualista e mais social.

Uma análise da definição romana do direito de propriedade como o direito que dá a ligação do homem à "coisa” decorre como o direito de propriedade estava intimamente associado ao caráter tangível do seu objeto.

Lembre-se de que o termo "coisa" corresponde ao termo res do latim, o qual, no sentido estrito, refere-se apenas àquelas que são dotadas de existência física, embora doutrinadores apontem para dúvidas, dentro do direito romano, quanto à possibilidade de res referir-se também a "outras entidades relevantes para o direito". ${ }^{6}$ Todavia, como se depreende da lição do prof. Cretella Júnior, transcrita a seguir, não se poderia dizer que o termo jurídico res teria chegado a abranger, no direito romano, as obras do espírito humano: "Nunca, porém, a mentalidade prática e concreta do romano chega a rotular como res certas entidades imateriais como serviços, prestaçóes pessoais, obras do espírito humano, irredutíveis a algo material"?

2 Código Civil, art. 1228, caput:

"Art. 1.228. O proprietário tem a faculdade de usar, gozar e dispor da coisa, e o direito de reavê-la do poder de quem quer que injustamente a possua ou detenha”.

3 Cf. CRETELLA JÚNIOR, 1995.

4 A versão do Corpus Iuris Civilis utilizada para a nossa consulta e para a nossa pesquisa é uma tradução do original, em latim, para o inglês: SCOTT, S. P. The civil law including the Twelve Tables, the Institutes of Gaius, the Rules of Ulpian, the Opinions of Paulus, the Enactments of Justinian, and the Constitutions of Leo. Cincinnati: Ed. The Central Trust Company, v. 1.

5 CRETELLA JÚNIOR, 1995, p. 169.

6 Ibid., p. 151:

O vocábulo res é tomado ora em sentido restrito, designando apenas o que cai sob os sentidos - tudo que tem existência real, no mundo concreto, ora tal sentido é alargado pelas investigaçóes e exigências dos juristas a ponto de abranger a res incorporales.

$7 \quad$ Ibid., p. 151. 
A evolução do direito de propriedade aponta uma primeira fase como sendo um direito voltado, principalmente, para o bem tangível, especialmente com vista à proteção dos bens imóveis.

O direito de propriedade sobre os bens móveis, inicialmente uma consequência lógica do direito sobre os imóveis, tornou-se mais elaborado ao longo da Idade Média e da Idade Moderna.

Por fim, foi somente há menos de trezentos anos que surgiu a proteção específica do direito da propriedade intelectual, com a edição das primeiras leis de copyright na Grã -Bretanha, como se verá adiante.

Nota-se que no texto do Corpus Iuris Civilis também há referências ao direito sobre a "propriedade incorpórea". Todavia, tal direito referia-se mais a "direitos", como o direito de herança e os direitos de usufruto ${ }^{8}$ e de servidão ${ }^{9}$, do que a direitos sobre propriedades intelectuais, como os direitos autorais e as patentes.

Curiosamente, apesar de a edição de lei de copyright somente ter surgido no final da Idade Média, um estudo mais aprofundado do Corpus Iuris Civilis aponta para algumas manifestaçóes da presença do embrião do Direito da Propriedade Intelectual no direito romano.

Tal manifestação está presente no trecho do Corpus Iuris Civilis que trata da chamada acessão física. A princípio, é considerado bem imóvel tudo aquilo que o homem incorporar definitivamente ao solo, uma vez que o Corpus Iuris Civilis determina que, por exemplo, a planta originada da semente lançada à terra pertence ao "dono da terra", ainda que a semente seja de terceiro. Ou seja, tudo aquilo que o homem incorporar permanentemente ao solo pertence ao dono do solo como um bem imóvel (ainda que proveniente de terceiro, com direito a indenização em certos casos). ${ }^{10}$

O interessante é que o Corpus vai além do exemplo da semente e preceitua que até mesmo os escritos de terceiros devem pertencer ao dono do papel, e não àquele que redigiu o texto:

(33) O escrito, também, ainda que se pense em escrito de ouro, pertence ao papiro, assim como as edificaçóes e as plantas pertencem ao solo; e, consequentemente, se Titius tiver escrito um poema, uma estória ou um discurso, no seu papiro, você, e não Titius, há de ser considerado como o dono do escrito. ${ }^{11}$ (tradução nossa)

8 Corpus Iuris Civilis, ed. cit., Título II, itens 1 e 2, v. 2.

9 Ibid., item 3 e Título III.

10 Assim também dispóe o art. 79 do Código Civil Brasileiro. Ressalta-se que o revogado Código Civil de 1916 era mais específico ao tratar, em seu art. 43, da "semente lançada ao solo" como um bem imóvel (trata-se de uma redação, digamos, mais próxima daquela do direito romano, adotada pelo texto do Corpus Iuris Civilis).

11 Corpus Iuris Civilis, ed. cit., Título I, item número 33, v. 2. 
Apesar desta regra geral da propriedade, seja por acessão física, no caso da semente lançada à terra, ou, ainda, no caso das edificaçóes, seja por acessão intelectual, no caso do escrito em papel de outrem, há algumas exceçóes no Corpus Iuris Civilis. Cuida-se de algumas dúvidas que são levantadas em hipóteses de pinturas, o que pode corresponder ao início do reconhecimento do direito de propriedade intelectual ou da proteção jurídica das chamadas "obras do espírito", conforme se depreende do texto que segue imediatamente ao número (33), transcrito anteriormente:

(34) Quando alguém pinta na tela de outrem, algumas pessoas pensam que a tela deveria pertencer à pintura, e outros são de opinião que a pintura, seja de que tipo for, é parte da tela. Parece-Nos (sic) preferível que a tela deva pertencer à pintura, uma vez que seria ridículo que uma pintura de Apelles ou de Parrhasius pudesse ser considerada a adição a uma tela. Assim, se uma pessoa estiver na posse de uma tela e o artista que a pintou resolve demandá-la, se este último não estiver disposto a pagar o preço da tela, ele pode ser impedido com base na fraude; mas se ele, que a pintou, estiver de posse dela, decorrerá que uma ação pode ser ajuizada contra ele pelo dono da tela, de forma que, se não pagar o preço da pintura, em todos os casos, ele também poderá ser impedido por uma exceção com fundamento na fraude; se ele, quem a pintou, obteve a posse da tela em boa-fé, é evidente que, se o artista ou qualquer terceiro adquirir a tela sub-repticiamente, o seu dono terá um direito de ação por furto. ${ }^{12}$ (tradução nossa)

Assim, pode-se concluir que até mesmo Justiniano já admitia que seria um erro considerar sempre que ao dono da tela pertenceria a pintura (é interessante que também o revogado Código Civil Brasileiro de 1916, em seu art. 62, excepcionava a pintura em relaçáo à tela, como benfeitorias acessórias). Esta regra demonstra a importância da propriedade intelectual como algo que se desprende de seu suporte físico. Em outras palavras, caso alguém seja dono do suporte físico onde está alguma propriedade intelectual, isto não lhe confere, por si só, algum direito de propriedade sobre a obra intelectual, ou a "obra do espírito".

O direito da Common Law, por seu turno, como um sistema bem menos elaborado e bem menos abstrato do que o direito romano, cuidou do direito de propriedade de duas formas, a "propriedade real" que se referia à terra e a "propriedade pessoal" que tratava dos bens móveis. ${ }^{13}$

A "propriedade real" da Common Law, dada a sua grande importância durante a Idade Média, por ser o local onde as pessoas moravam e dela retiravam o seu sustento,

12 Ibid., n. 34 .

13 Cf. BAKER, 1990. 
seja pela agricultura, seja pela criação de animais, era regulamentada pelo regime feudal (feudal tenure). O direito do regime feudal de propriedade (feudal tenure), que era bastante complexo, dados os direitos e as obrigaçóes dos senhores feudais e dos servos que habitavam a terra. ${ }^{14}$

O direito que regulamentava a "propriedade pessoal" da Common Law, por seu turno, foi bastante singelo, devido à falta de valor econômico dos bens móveis durante a Idade Média (o que era explicado pelo feudalismo e a excessiva valorização da terra, além do fato de a atividade comercial ter sido relativamente pequena durante o período feudal na Grã-Bretanha). É claro que mesmo durante o feudalismo já se desenvolvia o direito de propriedade sobre bens móveis na Grã-Bretanha, mas foi com o advento da Revoluçáo Industrial que o direito de propriedade pessoal, ou o direito de propriedade sobre os bens móveis consolidou-se.

A Common Law adotou o termo chattels $^{15}$ para o bem móvel (um termo que tem origem na língua francesa) e, segundo o regime da Common Law, o direito de propriedade sobre um chattel começava pela sua criação ou pela feitura de uma coisa nova. Trata-se da aplicaçáo da teoria romana da specificatio, segundo a qual a coisa pertence ao seu fabricante, àquele que, com as suas mãos, fez a coisa.

Assim como o direito da propriedade móvel decorreu da evoluçáo do feudalismo e, principalmente, da grande mudança trazida pelo comércio e pela Revolução Industrial, o Direito de Propriedade Intelectual também surgiu como decorrência da técnica, ou, mais especificamente, do surgimento da imprensa.

O primeiro direito de "copyright" foi conferido por um decreto real em 1556, na Grã-Bretanha, pouco após o advento da imprensa. ${ }^{16}$ Há discussôes na doutrina no que se refere à existência de outros decretos semelhantes e anteriores a esse, o que não invalida a importância do decreto de $1556 .^{17}$

A primeira lei inglesa que regulamentou o copyright foi o Statute of Anne, passada pelo parlamento britânico em 1710. Esta lei conferia aos autores o direito exclusivo sobre as suas obras, por um prazo de quatorze anos, renováveis por outro período de mais quatorze anos.

Deslocando de Justiniano e do direito comum da Inglaterra da Idade Médiapara a contemporaneidade, deparamo-nos com um interessante conflito que se apresenta para a proteção à propriedade intelectual. Como e o que proteger no caso da arte urbana? Qual

14 Ibid., p. 255.

15 Ibid., p. 428.

16 Cf. MERGES, 1997.

17 Ibid., p. 321. 
a propriedade a ser protegida pelo direito e a qual custo? $\mathrm{O}$ autor comete uma ilegalidade ou não ao expressar sua arte em prédios de terceiros, sejam públicos ou privados?

É interessante destacar que o próprio Banksy estampa em seu livro a provocação "copyright is for loosers", em uma provocação à ideia da propriedade intelectual. Ademais, quando Banksy pinta em certos locais ele sabe que a chance de a pintura ser apagada pelo dono do prédio existe. Tal probabilidade, por outro lado, tende a diminuir ao longo do tempo porque as obras de Banksy têm alcançado considerável exposição e consequente valorização, o que torna um "prêmio" para o dono do prédio receber as ilustraçóes, ainda que, em certos casos ou certos momentos, até mesmo provocativas, do artista.

A primeira interpretação do direito da propriedade intelectual é no sentido de proteger o autor da obra. Curiosa a situação fática de Banksy quando o próprio autor compartilha sua obra com o grande público, de certa forma "abrindo mão", despojando-se de seus direitos de autor sobre as suas criaçôes.

Um argumento que também poderia ser trazido à análise é a possibilidade do "enriquecimento sem causa" do dono do prédio quando ele se apropria da obra de Banksy e a vende para uma galeria de arte por soma expressiva. Todavia, por outro lado, teríamos que considerar também a renúncia do autor ao seus direitos de propriedade intelectual sobre a obra, ou até mesmo uma espécie de "doação implícita" dos direitos materiais sobre a criação em prol do dono do prédio. Não adentraremos aqui na análise dos direitos morais do autor Banksy sobre a obra, por entende-los fora do escopo deste artigo.

\section{Conclusões}

A contemporaneidade comporta novas manifestaçóes de arte urbana que não só inovam ao apresentarem criaçóes do espírito originais e muito criativas como também ao desafiarem certos pressupostos do direito da propriedade intelectual.

Ao produzir e publicizar obras de grande valor no espaço público, Banksy de certa forma renuncia aos seus direitos autorais. Ao mesmo tempo, galerias de arte podem pagar vultosas quantias para o dono do prédio no qual a obra foi fixada pelo autor sem muito interesse na proteção intelectual futura. A obra passa a ser de "propriedade" do acervo da galeria de arte, sem qualquer remuneração para o autor.

Tomando o direito de propriedade intelectual como ramo do direito que protege as criaçốes do espírito e que tem como norte a proteção do autor, sob tal perspectiva, um tanto tradicionalista, pode-se dizer, nos dias de hoje, a interpretação é toda construída em favor de Banksy como autor. Ocorre que, quando o próprio autor não se preocupa com a sua obra e pouco se importa com a futura comercializaçáo da mesma, pelo dono do prédio, a velha construção justiniana de acessão perde importância no caso concreto. 
Concluímos com duas interessantes frases de Banksy acerca do copyright e do direito sobre as suas criaçóes, expressas em obras por ele grafitadas em Londres e reproduzidas em seu livro, "copyright is lor loosers" e "I fought the law and I won...".

\section{Referências}

BAKER, J. H. An introduction to English legal history. 3. Ed. Londres: Butterworths, 1990. BANKSY. Wall and peace. Londres: Century, 2005.

. Guerra e Spray. Rio de Janeiro: Intrínseca, 2012.

CAUQUELIN, A. Arte contemporânea. São Paulo: Martins Fontes, 2005.

CRETELLA JÚNIOR, J. Curso de direito romano. 18. Ed. Rio de Janeiro: Forense, 1995.

ELLSWORTH-JONES, W. Banksy: the man behind the wall. New York: St. Martin's Press, 2012.

JAMESON, F. Pós-modernidade e sociedade de consumo. In: Revista Novos Estudos no. 12. São Paulo, CEBRAP.

MERGES, Robert P. et al. Intellectual property in the new technological age. New York: Aspen \& Law Business, 1997.

SCOTT, S. P. The civil law including the Twelve Tables, the Institutes of Gaius, the Rules of Ulpian, the Opinions of Paulus, the Enactments of Justinian, and the Constitutions of Leo. Cincinnati: Ed. The Central Trust Company, v. 1. 